\title{
Studies on the Repellency of some Plant Distillates to Adult Sitophilus sp.
}

\author{
V. K. Ganesalingam and V. Shuvanandarajah \\ Department of Zoology, University of Jaffna, Jaffna, Sri Lanka \\ (Date of receipt: 06 March 1984) \\ (Date of acceptance: 12 November 1984)
}

\begin{abstract}
The volatile distillates of leaves of Ocimum sanctum, Vitex negundo, Azadirachta indica and Citrus aurantifolia were investigated for repellency to Sitophilus sp. in the laboratory using a $\mathrm{Y}$-shaped olfactometer. Of the plant distillates tested $O$. sanctum was found to be the most effective repellent to Sitophilus sp. The other plant distillates tested showed repellency of a significantly lesser degree than $O$. sanctum. The repellency of the synergistic combination of volatile distillates of $O$. sanctum and $A$. indica was found to be as effective as that of $O$. sanctum alone. With regard to the duration of the repellent effect of the steam distillates (crude water extracts) of the plants tested, it was found that the freshly prepared and 10 day old preparation of $O$. sanctum had the same effect. The 20 and 30 day old preparation of $O$. sanctum showed significantly lesser repellency than the freshly prepared or 10 day old preparation of $O$. sanctum.
\end{abstract}

\section{Introduction}

The rice weevil (Sitophilus sp.) is an important pest of rice in some parts of Sri Lanka.2,3 Juriansz ${ }^{5}$ made a preliminary study on the efficacy of essential oils such as Lime leaf oil as a repellent to Sitophilus. Krishnarajah and Ganesalingam ${ }^{6}$ have shown that the steam distillates of certain plants repelled Sitotroga cerealella. The present study was carried out to evaluate the repellency of the extracts of certain plants to adult Sitophilus sp.

\section{Materials and Methods}

Sitophilus culture was maintained on rice in the laboratory. The culture contained Sitophilus oryzae (L.) and Sitophilus zeamais Mostch. which usually occur together in storage. ${ }^{3,4}$

The leaf samples were steam distilled and the distillate was extracted with ether. The water from the ether extract was removed by anhydrous sodium sulphate and the ether was removed under reduced pressure. This volatile extract was used in Experiments 1 and 2. In Experiment 3 the volatile matter used was direct steam distillate after separation in a separating funnel (crude water extract). The leaves of the following plants were used in this study: 

a. Ocimum sanctum L. - Madura-tala (S); Tulasi (T)
b. Vitex negundo (L.) - Nikka (S); Nochchi (T)
c. Azadirachta indica (A. Juss.) - Kohomba (S); Vembu (T)
d. Citrus aurantifolia (Christan) Swingle - Dehi (S); Elumichai (T)

The repellency of the extract was determined using a Y-shaped olfactometer (Figure 1). A filter paper $\left(1.0 \mathrm{~cm} \times 0.3 \mathrm{~cm}\right.$ ) moistened with $3 \mu_{1}$ of the extract, was placed in one arm; a filter paper of the same size moistened with $3 \mu 1$ of distilled water was placed in the other arm as a control. The opening of the arms of the Y tube was plugged with cotton wool. Ten adult insects of the same age were introduced into the main arm. The insects moved forwards and subsequently moved either into the arm containing the repellent or into the other arm. The number of insects recorded in the arm containing distilled water represented the number repelled by the extract. This was repeated keeping the extract in the other arm. Fifteen replicates were taken in each experiment. However some beetles did not show any response in the experiment while some of them died during the experimental period, and their numbers were not taken into account. The olfactometer was washed with distilled water and dried and the position of the arms were changed at every replicate. The whole experiment was carried out in a dark room with ten watts light kept $60 \mathrm{~cm}$ away from the front part of the olfactometer. Preliminary experiments were conducted in order to confirm that the movement of the beetles towards either arm was random by introducing the beetles into the main stem of the olfactometer without test materials in it. Nearly equal number of beetles moved to either arm when 50 beetles were introduced into the main stem in five replicates.

The experiments were conducted at room temperature $30^{\circ} \mathrm{C} \pm 2$, and $\mathrm{R} . \mathrm{H}$ $80 \% \pm 2$.

\section{Results}

When the number of Sitophilus sp.. moving towards the various volatile distillates such as $O$. sanctum, $V$. negundo, $A$. indica and $C$. aurantifolia was compared with that moving towards distilled water by $\mathrm{x}^{2}$ test, it was found that the repellency of the extracts of these plants differ from one another ( $P>5 \%$ for each extract). Anova test applied to the results showed that $O$. sancturn had a repellency that was significantly higher than that of other plants tested and the repellency of the distillates of the other plants did not show any significant difference among themselves. 


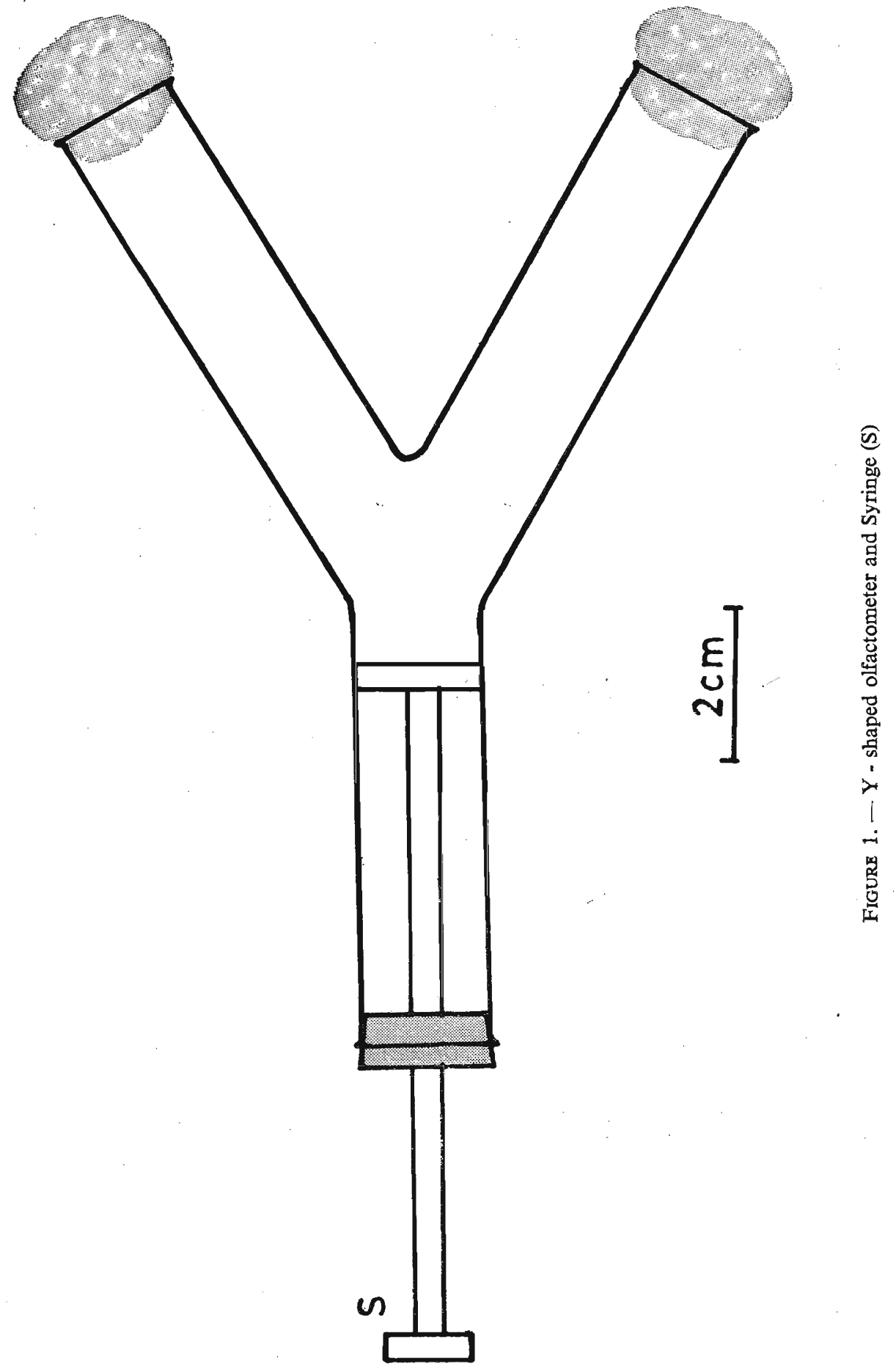


$(F=3.56 ; F=7.45 ; P>5 \% ;$ L.S.D. $=10.460)$ (Table 1.)

TABle 1. The number of Sitophilus sp. moving towards either distilled water or the extract in olfactometer

\begin{tabular}{ccccccccc}
\hline \multicolumn{2}{c}{ Ocimum sanctum } & \multicolumn{2}{c}{ Azadirachta indica } & \multicolumn{2}{c}{ Vitex negundo } & \multicolumn{2}{c}{ Citrus aurantifolia } \\
\hline $\begin{array}{c}\text { distilled } \\
\text { water }\end{array}$ & Extract & $\begin{array}{l}\text { distilled } \\
\text { water }\end{array}$ & Extract & $\begin{array}{l}\text { distilled } \\
\text { water }\end{array}$ & Extract & $\begin{array}{l}\text { distilled } \\
\text { water }\end{array}$ & Extract \\
\hline 8 & 2 & 8 & 2 & 6 & 1 & 6 & 0 \\
7 & 0 & 6 & 4 & 5 & 4 & 3 & 4 \\
6 & 1 & 4 & 3 & 7 & 1 & 3 & 3 \\
7 & 0 & 8 & 2 & 5 & 4 & 6 & 2 \\
9 & 1 & 7 & 2 & 5 & 4 & 6 & 1 \\
8 & 2 & 8 & 2 & 7 & 1 & 3 & 3 \\
7 & 1 & 4 & 3 & 5 & 4 & 3 & 4 \\
8 & 1 & 7 & 2 & 5 & 4 & 6 & 2 \\
8 & 2 & 6 & 4 & 5 & 3 & 6 & 0 \\
6 & 1 & 8 & 2 & 6 & 1 & 6 & 1 \\
7 & 0 & 4 & 3 & 5 & 4 & 6 & 2 \\
7 & 1 & 6 & 4 & 5 & 3 & 6 & 1 \\
9 & 1 & 8 & 2 & 7 & 1 & 3 & 3 \\
7 & 0 & 7 & 2 & 6 & 1 & 3 & 4 \\
6 & 1 & 6 & 3 & 5 & 4 & 5 & 2 \\
Total 110 & 14 & 97 & 40 & 84 & 40 & 71 & 32 \\
\hline
\end{tabular}

O. sanctum $>V$. negundo $\triangle A$. indica $\triangle$ C. aurantifolia.

When the number of Sitophilus sp. moving away from the synergistic distillate of $O$. sanctum and $A$. indica was compared to that moving away from $O$. sanctum and $A$. indica individually using $\mathrm{x}^{2}$ test and Anova test, it was found that the distillates of $O$. sanctum are as effective as the synergistic combination of $O$. sanctum and $A$. indica and is more effective than $A$. indica alone.

$(\mathrm{F}=2.42 ; \mathrm{f}=36.49 ; \mathrm{P}>5 \%$;.S.D. $=7.24)$ (Table 2).

TABle 2. The number of Sitophilus sp. moving towards either distilled water or the synergistic combination of $O$. sanctum and $A$. indica, $O$. sanctum and $A$. indica separately in an olfactometer

\begin{tabular}{cccccc}
\hline $\begin{array}{c}\text { Ocimum sanctum } \\
\text { Azadirachta indica }\end{array}$ & \multicolumn{2}{c}{ Ocimum sanctum } & \multicolumn{2}{c}{ Azadirachta indica } \\
\hline $\begin{array}{l}\text { Distilled } \\
\text { Water }\end{array}$ & Extract & $\begin{array}{c}\text { Distilled } \\
\text { water }\end{array}$ & Extract & water & Extract \\
\hline 7 & 0 & 6 & 3 & 6 & 3 \\
7 & 1 & 7 & 1 & 4 & 2 \\
8 & 1 & 9 & 0 & 4 & 3 \\
5 & 1 & 8 & 0 & 6 & 3 \\
\end{tabular}


(Table 2 Continued)

\begin{tabular}{|c|c|c|c|c|c|c|}
\hline & \multicolumn{2}{|c|}{$\begin{array}{c}\text { Ocimum sanctum } \\
+ \\
\text { Azadirachta indica }\end{array}$} & \multicolumn{2}{|c|}{ Ocimum sanctum } & \multicolumn{2}{|c|}{ Azadirachta indica } \\
\hline & $\begin{array}{l}\text { Distilled } \\
\text { Water }\end{array}$ & Extract & $\begin{array}{l}\text { Distilled } \\
\text { water }\end{array}$ & Extract & $\begin{array}{l}\text { Distilled } \\
\text { water }\end{array}$ & Extract \\
\hline & 6 & 1 & 7 & 2 & 6 & 2 \\
\hline & 8 & 1 & 8 & 1 & 4 & 5 \\
\hline & 6 & 1 & 6 & 1 & 6 & 1 \\
\hline & 5 & 1 & 6 & 0 & 5 & 4 \\
\hline & 6 & 1 & 6 & 3 & 4 & 5 \\
\hline & 7 & 1 & 6 & 0 & 4 & 3 \\
\hline & 5 & 1 & 6 & 1 & 4 & 2 \\
\hline & 8 & 1 & 7 & 2 & 5 & 4 \\
\hline & 7 & 1 & 6 & 0 & 4 & 2 \\
\hline & 8 & 1 & 7 & 2 & 4 & 3 \\
\hline & 7 & 1 . & 8 & 1 & 4 & 5 \\
\hline Total & 100 & 14 & 103 & 17 & 70 & 47 \\
\hline
\end{tabular}

O. sanctum $\triangle O$. sanctum + A. indica $>A$. indica

With regard to the duration of the repelling effect of the distillates of the plant extract (crude water extract) of plants tested, when the mean percentages of the number of Sitophilus $s p$. moving away from the distillate was compared in respect to age of the plant extracts by Anova test, it was found that the freshly prepared and ten day old extracts of $O$. sanctum had the same effect. However, 20 and 30 day old distillates of the $O$. sanctum showed significantly less repellency than the freshly prepared or ten day extracts of $O$. sanctum. Similarly the freshly prepared, 10, 20 and 30 day old extracts of the other plants used in the experiment also showed a significantly lower repellency than the freshly prepared or ten day old extracts of $O$. sanctum.

$(F=15.239 ; \mathrm{F}=11.92 ; \mathrm{P}>5 \% ;$ L.S.D. $=9.118)$ (Table 3$)$.

TABLE 3. Effect of time on the repelling effect of the plant extracts (Crude water extracts) to Sitophilus sp.

\begin{tabular}{lllll}
\hline Time & \multicolumn{3}{c}{ Mean percentage of Sitophilus sp. moving away from the extracts } \\
\hline $\begin{array}{l}\text { Ocimum } \\
\text { sanctum }\end{array}$ & $\begin{array}{l}\text { Vitex } \\
\text { negundo }\end{array}$ & $\begin{array}{c}\text { Azadirachta } \\
\text { indica }\end{array}$ & $\begin{array}{c}\text { Citrus } \\
\text { aurantifolia }\end{array}$ \\
\hline 0 day & 91.705 & 68.819 & 71.094 & 64.920 \\
10 days & 74.954 & 60.928 & 63.906 & 52.687 \\
20 days & 67.873 & 54.0 & 67.620 & 55.716 \\
30 days & 67.150 & 58.453 & 52.381 & 52.064 \\
\hline
\end{tabular}

O. sanctum (fresh) $\triangle O$. sanctum (10 day) $>O$. sanctum $(20-30$ day). 


\section{Discussion}

Juriansz $z^{5}$ observed repulsion of Sitophilus to lime leaf oil. A comparative study of repulsion of Sitophilus to various plant extracts was made in this investigation, and it was found that the extract of $O$. sanctum was the most effective repellent used to the rice weevil. It has been recorded however, that Vitex negundo is the most effective repellent to Sitotroga cerealella. ${ }^{6}$ The plant extract of Azadirachta indica was reported to be an effective repellent to Sitotroga cerealella. ${ }^{x}$ The products of some plants, treated or untreated, are useful as insect repellents. However, it appears that the repellent for one pest species may not be effective for another. The extraction of plant products without loss of their essential oils will be of great value in selecting the appropriate repellent to each pest.

It has been recorded that the effect of two repellents was greater than the repellency of the individual plant extracts. ${ }^{7,8}$ However, in this study the synergistic mixture of $O$. sanctum and $A$. indica seems to be as effective as $O$. sanctum when used singly, and is more effective than $A$. indica.

In this study it was found that in the case of all plants used the freshly prepared extract was as effective as the 10 day old, while preparations which were older became progressively less effective with increasing age.

\section{References}

1. Abraham, C. C., Thomas, B., Karunakaran, K. \& Gopalakrishnan, R. (1972). Relative efficiency of some plant products in controlling infestation by the Angoumois grain moth Sitotroga cerealella Olivier (Gelechiidae: Lepidoptera) infesting stored paddy in Kerala. Agri. Res. J. Kerala 10 (1), 59-60.

2. Ganesalingam, V. K. (1974). Insect pests of rice stores. Proc. Cey. Ass. Advmt. Sci. $30(1), 94-95$.

3. Ganesalingam, V. K. (1975). A study of insects in four rice stores in the Kandy District in Sri Lanka. Ceylon. J. Sci. (Bio. Sci.) 12 (1), 30-46.

4. Ganesalingam, V. K. (1977). Insects in paddy and rice in storage in the Kandy District. Cey. J. Sci. (Bio. Sci.) 12 (2), 169-176.

5. Juriansz, E. (1975). Response of Sitophilus the common weevil of rice and other food products in Sri Lanka to essential oils in olfactometer tests. J. Natn. Sci. Coun. Sri Lanka 3 (2), 145-148.

6. Krishnarajah, S. R. \& Ganesalingam, V. K. (1977). Preliminary investigation in control of Sitotroga cerealella (Olivier) by local repellents. Proc. Sri Lanka Ass. Advmt. Sci. 33 (1). 51.

7. Krishnarajah, S. R., Senanayake, U. M. \& Ganesalingam, V. K. (1980). Effects of tho hydrocarbons present in the essential oils on Sitotroga cerealella (Lepidoptera : Gelechiidae), Proc. Sri Lanka Ass. Advmt. Sci. 36 (1) 62.

8. Su, H. C. R. (1977). Insecticidal properties of black pepper to rice weevils and cowpea weevils. J. Econ. Entomol. 70 (1) 18-21. 